\title{
Does Vitamin D Deficiency Cause Hypertension? Current Evidence from Clinical Studies and Potential Mechanisms
}

\author{
M. Iftekhar Ullah, ${ }^{1}$ Gabriel I. Uwaifo, ${ }^{2,3}$ William C. Nicholas, ${ }^{2}$ and Christian A. Koch ${ }^{2,3}$ \\ ${ }^{1}$ Division of General Internal Medicine and Hypertension, Department of Medicine, \\ University of Mississippi Medical Center, Jackson, MS 39216, USA \\ ${ }^{2}$ Division of Endocrinology, University of Mississippi Medical Center, Jackson, MS 39216, USA \\ ${ }^{3}$ Department of Medicine, G.V. (Sonny) Montgomery VA Medical Center, Jackson, MS 39216, USA
}

Correspondence should be addressed to M. Iftekhar Ullah, mullah@medicine.umsmed.edu

Received 30 April 2009; Revised 26 July 2009; Accepted 29 August 2009

Academic Editor: Vin Tangpricha

Copyright ( $) 2010$ M. Iftekhar Ullah et al. This is an open access article distributed under the Creative Commons Attribution License, which permits unrestricted use, distribution, and reproduction in any medium, provided the original work is properly cited.

\begin{abstract}
Vitamin D deficiency is widely prevalent across all ages, races, geographical regions, and socioeconomic strata. In addition to its important role in skeletal development and calcium homeostasis, several recent studies suggest its association with diabetes, hypertension, cardiovascular disease, certain types of malignancy, and immunologic dysfunction. Here, we review the current evidence regarding an association between vitamin D deficiency and hypertension in clinical and epidemiological studies. We also look into plausible biological explanations for such an association with the renin-angiotensin-aldosterone system and insulin resistance playing potential roles. Taken together, it appears that more studies in more homogeneous study populations are needed before a firm conclusion can be reached as to whether vitamin D deficiency causes or aggravates hypertension and whether vitamin $\mathrm{D}$ supplementation is safe and exerts cardioprotective effects. The potential problems with bias and confounding factors present in previous epidemiological studies may be overcome or minimized by well designed randomized controlled trials in the future.
\end{abstract}

\section{Introduction}

Vitamin D deficiency has been described worldwide [1]. In addition to its important role in skeletal development and calcium homeostasis, it has been suggested that low vitamin D nutritional status may have an impact on extraskeletal health including increased risk of certain types of malignancy, immunologic dysfunction, diabetes, and cardiovascular disease $[2,3]$. The socioeconomic burden of the above chronic diseases that have been linked to vitamin $\mathrm{D}$ deficiency is enormous. The estimated yearly total health costs for persons in the United States with heart disease and hypertension was 148 billion US dollars in 1996 [4]. Since both hypertension and vitamin D deficiency are highly prevalent worldwide, establishing an association among these two may potentially have wide public health implications but may also be the result of the high prevalence of both conditions rather than a causative link between them. Given the low cost and low side effect profile of vitamin D, replacing it in vitamin $\mathrm{D}$ deficient populations may help reduce the burden of this condition and simultaneously reduce cardiovascular risk.

\section{Biological Roles of Vitamin D in Humans}

There are two main sources of vitamin $\mathrm{D}$ available to humans, from direct exposure to sunlight (Solar UV-B) and from the diet or dietary supplements. Solar UV-B radiation penetrates the skin and converts 7-dehydrocholesterol to previtamin D3, which, in turn, converts rapidly to vitamin D3. The oily fishes such as salmon, sardines, and mackerel, egg yolks, and fish oils such as cod liver oil contain vitamin D naturally. Fortified milk, cereal, juice, and yogurt are dietary sources in North America. The cutaneous synthesis of vitamin $\mathrm{D}$ may vary widely in different populations depending on their availability of sun exposure as well as the actual sun exposure of the bare skin when the sun light is available. Skin pigmentation with melanin is 
a limiting factor in the cutaneous synthesis of vitamin D. Melanin acts as an effective natural sunscreen and, therefore, increased skin pigment can greatly reduce the solar UV-Bmediated cutaneous synthesis of vitamin D3 by as much as $99 \%$ [5].

Vitamin D from the skin and diet is metabolized in the liver to 25-hydroxyvitamin $\mathrm{D}[25(\mathrm{OH}) \mathrm{D}]$. This $25(\mathrm{OH}) \mathrm{D}$ is metabolized in the kidneys by the enzyme 25 hydroxyvitamin D- $\alpha$-hydroxylase (CYP27B1) to its active form, 1,25-dihydroxyvitamin $\mathrm{D}\left[1,25(\mathrm{OH})_{2} \mathrm{D}\right]$. The renal production of $1,25(\mathrm{OH})_{2} \mathrm{D}$ is closely regulated by serum parathyroid hormone (PTH) levels as well as by serum calcium and phosphorus levels [6]. The absorption of renal calcium as well as intestinal calcium and phosphorus is increased in the presence of $1,25(\mathrm{OH})_{2} \mathrm{D}$ [7].

The $1,25(\mathrm{OH})_{2} \mathrm{D}$ ligand binds to the vitamin $\mathrm{D}$ receptor (VDR) and triggers an increase in intestinal absorption of both calcium and phosphorus. Vitamin D is also involved in bone formation, resorption, and mineralization as well as in maintaining neuromuscular function. Circulating $1,25(\mathrm{OH})_{2} \mathrm{D}$ reduces the serum PTH level directly by decreasing parathyroid gland activity and indirectly by increasing serum calcium. It also regulates bone metabolism in part by interacting with the VDR in osteoblasts to release biochemical signals, leading to formation of mature osteoclasts. The osteoclasts release collagenases and hydrochloric acid to dissolve the matrix and mineral, releasing calcium into the blood [8].

Decreasing vitamin D levels impairs the calcium and phosphorus homeostasis in the body. Vitamin D is primarily responsible for regulating the efficiency of intestinal calcium absorption. Its deficiency decreases the absorption of calcium from the small intestine. This leads to a cascade of events by increasing the production and release of PTH into the circulation, which restores calcium homeostasis by increasing tubular reabsorption of calcium in the kidney, increasing bone calcium mobilization from the bone, and enhancing the production of $1,25(\mathrm{OH})_{2} \mathrm{D}[8]$.

Even though the bone, small intestine, and kidneys are the primary organs responsive to vitamin $\mathrm{D}$, the effects of vitamin $\mathrm{D}$ in the body are more far reaching. The vitamin $\mathrm{D}$ receptor (VDR) has been identified in many cell types, tissues, and organs, including those not typically associated with calcium homeostasis and bone metabolism indicating that vitamin $\mathrm{D}$ may also be involved in important biological processes beyond calcium homeostasis [9]. Some of these include the heart, vascular smooth muscle, endothelium, stomach, pancreas, brain, skin, gonads, and various cells of the immune system [8]. VDR is a steroid hormone nuclear receptor that binds to $1,25(\mathrm{OH})_{2} \mathrm{D}$ with high affinity and mediates transcriptional gene regulation [8]. Recent evidence suggests that the VDR is also involved in mediating noncalcemic effects of vitamin $\mathrm{D}$ and its analogues and may play a vital role in disease prevention and maintenance of extra-skeletal health. A number of recent studies involving cell culture and VDR knockout mice have suggested that vitamin $\mathrm{D}$ plays a critical role in regulating the Renin-Angiotensin System (RAS) and thus influencing the regulation of blood pressure $[10,11]$.

\section{Observations of Racial and Geographical Factors Influencing Vitamin D Nutritional Status}

There are various cultural, social, racial, and geographical factors that may influence the inadequacy of vitamin $\mathrm{D}$. Degree of exposure of bare skin to the sunlight is an important factor in determining vitamin $\mathrm{D}$ status. A change in season or latitude may have a dramatic effect on the cutaneous production of cholecalciferol. In the INTERSALT study, which examined $>10000$ participants from around the world, the systolic and diastolic blood pressure were significantly and positively associated with distance from the equator $[12,13]$. In Edmonton, Canada $\left(52^{\circ} \mathrm{N}\right)$, the photosynthesis of precholecalciferol essentially ceases by mid-October and does not resume until mid-April, thus influencing the vitamin D concentration in that population [14]. Covering the entire body with clothing (as customary in women in some religions), use of sunscreen and glass shielding may significantly reduce or completely eliminate the production of vitamin D3 in the skin [15]. Biological factors that inhibit cutaneous vitamin D synthesis and bioavailability include skin pigmentation, medication use, body fat content, fat malabsorption, and age [16]. Increased skin pigmentation can reduce cutaneous vitamin D3 production as much as $99.9 \%$, which may explain, at least in part, the higher prevalence of vitamin D deficiency in the African American population [5]. In addition, ethnic-specific polymorphisms of the vitamin $\mathrm{D}$ receptor gene and its promoter may influence vitamin $\mathrm{D}$ action including individual calcium absorption.

\section{Epidemiological Evidence of the Relationship between Vitamin D and Hypertension}

Several clinical and epidemiological studies have shown that there may be an association between hypertension and vitamin D status as well as calcium metabolism. In 1980, McCarron et al. [17] postulated that disorders of calcium metabolism including hyperparathyroidism may be related to development of hypertension and showed in his study that hypertensive patients had a significant $(P<.005)$ relative hypercalciuria when compared to normotensives. In the early 1990s, Cooper and Rotimi observed geographic differences in blood pressure among individuals of African origin. He found that those residing in the northern regions had higher blood pressure than those residing closer to the equator [18]. Langford and Watson [19] noted that children from rural Mississippi had higher blood pressure and low calcium intake compared to urban children. Zemel et al. [20, 21] found that the intake of calcium in salt-sensitive blacks can reduce blood pressure and cause partial regression of left ventricular hypertrophy. Other investigators have found similar results $[22,23]$.

Scragg et al. [24] recently reported their findings of the relationship between serum $25(\mathrm{OH}) \mathrm{D}$ concentration and blood pressure. The authors studied the data from the third National Health and Nutrition Examination Survey 
(NHANES III), a nationally representative cross-sectional survey of the noninstitutionalized population in the United States carried out during 1988-1994. A signicant inverse association was reported between serum $25(\mathrm{OH}) \mathrm{D}$ concentration and blood pressure that was evident even after adjustment for variables including age, gender, ethnicity, and physical activity. After dividing the subjects into $25(\mathrm{OH}) \mathrm{D}$ quintile groups, the authors found that the mean systolic blood pressure was $3.0 \mathrm{~mm} \mathrm{Hg}$ lower and the diastolic blood pressure was $1.6 \mathrm{~mm} \mathrm{Hg}$ lower in the highest quintile [serum $25(\mathrm{OH}) \mathrm{D} \geq 85.7 \mathrm{nmol} / \mathrm{L}]$, compared with the lowest quintile [serum $25(\mathrm{OH}) \mathrm{D} \leq 40 \mathrm{nmol} / \mathrm{L}$ ] of vitamin $\mathrm{D}$ status. The mean difference in systolic BP was higher among nonHispanic blacks than Mexican Americans compared to non-Hispanic whites, after adjusting for age and sex. This difference in systolic BP in non-Hispanic blacks (compared to non-Hispanic whites) becomes blunted when quintile of vitamin $\mathrm{D}$ is added to the model, indicating that higher prevalence of vitamin D deficiency in non-Hispanic blacks has contributed to the higher mean systolic BP in this group of population.

Judd et al. [25] also analyzed the NHANES III survey data and showed a statistically significant inverse association between circulating $25(\mathrm{OH}) \mathrm{D}$ concentrations and systolic blood pressure. However, this association was not statistically significant when age was included in the model, nor was it significant in the black subpopulation.

Martins et al. [26] found that a low vitamin D level was associated with a higher risk of having hypertension. This cross-sectional study, using the NHANES III data, looked at the association between serum $25(\mathrm{OH}) \mathrm{D}$ and several cardiovascular disease risk factors, including hypertension, in the adult US population. The $25(\mathrm{OH}) \mathrm{D}$ levels were found to be significantly lower in women, elderly persons ( $\geq 60$ years), racial/ethnic minorities, and participants with obesity, hypertension, and diabetes mellitus. The adjusted prevalence of hypertension in adults in the US was 30\% higher in the lowest quartile compared to the highest quartile of serum $25(\mathrm{OH}) \mathrm{D}$.

In summary, the NHANES III data analyses showed an inverse association between blood pressure and vitamin D concentration, even though it is not consistent across all different groups of subpopulations in the above three analyses. This is most likely due to the differences in the variable adjusted and the samples included in the analyses.

Forman et al. [27] prospectively investigated the independent association between plasma $25(\mathrm{OH}) \mathrm{D}$ levels and risk of incident hypertension. Two prospective cohort studies that included 613 men from the Health Professionals' Follow-Up Study and 1198 women from the Nurses' Health Study with measured 25(OH)D levels were followed for 4 to 8 years. After this follow-up, the multivariable relative risk (RR) of incident hypertension among those whose measured plasma $25(\mathrm{OH}) \mathrm{D}$ levels were $<15 \mathrm{ng} / \mathrm{mL}$ (compared with those whose levels were $>30 \mathrm{ng} / \mathrm{mL}$ ) was 6.13 in men and 2.67 in women. These findings provide support in favor of an association between vitamin D deficiency and the increased risk of hypertension.

\section{Clinical Studies Showing Effect of Vitamin D Supplementation on Blood Pressure}

Increasing vitamin $\mathrm{D}$ level in the blood directly or indirectly has been shown to reduce blood pressure in some studies. Krause et al. randomly assigned 18 patients with mild hypertension to receive UV-B or UV-A exposure, 3 times weekly for 6 weeks [28]. In this study, he found that there was a $162 \%$ rise in plasma $25(\mathrm{OH}) \mathrm{D}$ in the UV-B group along with a drop in both systolic and diastolic blood pressure by $6 \mathrm{~mm} \mathrm{Hg}$. No change in the blood pressure was observed with UV-A exposure (UV-A does not produce vitamin D). In another randomized, placebo-controlled study in 145 elderly women showed that $800 \mathrm{IU}$ of vitamin D3 plus $1200 \mathrm{mg}$ of calcium significantly reduced blood pressure by $9.3 \%$ after 8 weeks, whereas treatment with $1200 \mathrm{mg}$ of calcium alone reduced blood pressure by only $4.0 \%(P=.02)$ [29].

\section{Epidemiological Studies Showing No Relationship between Vitamin D and Hypertension}

Even though the majority of recent clinical studies cited earlier in this review support the hypothesis of an inverse association between the vitamin D serum level and blood pressure, there have been studies that contradict this hypothesis as well. For instance, a large prospective study by Forman et al. in 2005 found no association between vitamin D intake from diet and supplements and the risk of incident hypertension [30].

In the Women's Health Initiative Calcium/Vitamin D Trial by Margolis et al. supplementation of $1000 \mathrm{mg}$ of elemental calcium plus $400 \mathrm{IU}$ of vitamin D3 daily (versus placebo) in a random double-blind fashion did not show any significant decrease in incidence hypertension after a median followup time of 7 years [31]. In another longitudinal, placebo-controlled, double-blind study by Orwoll Oviatt, normotensive men were treated with a calcium and cholecalciferol supplement, or placebo, for 3 years without any demonstrable effect on systolic, diastolic, or mean arterial pressure [32]. The randomized double-blind trial by Scragg et al. with a vitamin D supplementation at a single dose of $2.5 \mathrm{mg}$ in winter months did not show any significant decrease in blood pressure after 5 weeks when compared to placebo [33]. Snijder et al. studied the participants of the Longitudinal Aging Study in Amsterdam and found that blood pressure in this population was not inversely associated with the serum $25(\mathrm{OH}) \mathrm{D}$ level but was positively correlated with serum PTH [34]. Another study conducted in Germany showed similar findings [35].

\section{Possible Cause/Explanation for Lack of an Association between the Vitamin D Level and Blood Pressure}

The reasons behind these contradictory findings in the above mentioned studies about an association of blood pressure 
and vitamin $\mathrm{D}$ could be multiple. The earlier observational study by Forman did not have information about the exact amount of vitamin D intake and it was estimated from a semiquantitative food frequency questionnaire [30]. The diagnosis of hypertension was also only self-reported in this study, not by direct measurement of the participant's blood pressure. Unless the subjects with lower intake of vitamin D had clinically significant deficiency, an association between vitamin $\mathrm{D}$ status and blood pressure is likely to be missed. If vitamin $\mathrm{D}$ decreased blood pressure mainly via inhibiting the RAS, we may not see any decrease in blood pressure if the subjects do not have a vitamin $\mathrm{D}$ level below a certain threshold, at which a hyperreninemic state is created. Thus, vitamin D supplementation would also be unlikely to produce any decrease in blood pressure in normotensive subjects as their plasma renin is likely to be normal. The study by Scragg et al. measured blood pressure response only after 5 weeks of vitamin D intake which may be too early to show any clinical response [33]. In the study by Snijder et al., the authors postulated that the lack of an association between blood pressure and vitamin $\mathrm{D}$ level may be due to the relatively high levels of vitamin $\mathrm{D}$ in that population [34].

The more recent randomized controlled trial by Margolis et al. [31] was a substudy of the Women's Health Initiative (WHI) that was originally designed to look at hip fractures and colorectal cancers. In an editorial comment about this study, Geleijnse mentioned that there may be several flaws in this study [36]. The level of compliance to vitamin D/calcium was only modest $(60 \%$ women reported taking $>80 \%$ study medications); BP measurement criteria were not strict at the site visit and were probably not blinded to staff and participants. Nearly half of the participants were already hypertensive at baseline and $28 \%$ used antihypertensive medications. Incident hypertension was self reported, based on asking women twice per year if they had been started on new "pills for hypertension." The vitamin D dose used in the study (400 IU) was fairly low, and the estimated increase of the vitamin $\mathrm{D}$ level with this supplementation in this study population was about $2 \mathrm{ng} / \mathrm{mL}(5 \mathrm{nmol} / \mathrm{L})$ [37] which may be too low to produce any clinical effect on blood pressure. In the study by Judd et al., [25] the authors suspected that using a $25(\mathrm{OH}) \mathrm{D}$ cutoff point of $<80 \mathrm{nmol} / \mathrm{L}$ to define vitamin D insufficiency had placed the majority of blacks (92\%) into the vitamin deficient group, leaving too few people in the nondeficient group, resulting in failure to detect a statistically significant association between hypertension and vitamin $\mathrm{D}$. The inverse association between blood pressure and $25(\mathrm{OH}) \mathrm{D}$ concentration was further weakened after controlling for age because vitamin $\mathrm{D}$ production decreases in older adults secondary to lower skin concentrations of 7-dehydrocholesterol (the precursor to $\mathrm{D}_{3}$ ). Increasing age is also associated with decreased concentrations of $25(\mathrm{OH}) \mathrm{D}$ [38]. Since these two variables are highly correlated, adjusting for one (age, in this case) had weakened the association of the other variable (vitamin D level) with systolic blood pressure in this study.

\section{Evidence of a Relationship between Vitamin D and Preeclampsia}

Maternal vitamin D deficiency is a widespread public health problem. In a recent study, it was found that approximately $29 \%$ of black pregnant women and $5 \%$ of white pregnant women residing in the northeastern United States had vitamin $\mathrm{D}$ deficiency $(25(\mathrm{OH}) \mathrm{D}<37.5 \mathrm{nmol} / \mathrm{L})$, whereas $54 \%$ of black women and $47 \%$ of white women had vitamin D insufficiency with a serum $25(\mathrm{OH}) \mathrm{D}$ levels of $37.5-80$ $\mathrm{nmol} / \mathrm{L}$ [39]. Preeclampsia is a pregnancy-specific syndrome that affects approximately $3 \%-7 \%$ of first pregnancies. The known racial disparity in preeclampsia, with black women being more likely to develop severe preeclampsia and suffer greater morbidity associated with the disorder than white women [40], is consistent with the hypothesis that vitamin $\mathrm{D}$ deficiency may be involved in the development of this condition.

Hyppönen et al. [41] investigated the association between infant vitamin D supplementation and development of preeclampsia in those persons later in life when they become pregnant. The investigators used data on 2969 women born in the Northern Finland Birth Cohort 1966 of whom $68(2.3 \%)$ had preeclampsia in their first pregnancy. Risk of preeclampsia was halved ((OR) 0.49, $95 \%$ CI $0.26-0.92)$ in participants who had received vitamin D supplementation regularly during the first year of life. Studies of seasonal patterns in preeclampsia showed that the incidence of preeclampsia was the lowest in summer, when sunlight is plentiful and serum $25(\mathrm{OH}) \mathrm{D}$ concentrations are at their peak, and the highest in winter, when synthesis of vitamin D3 is limited in temperate zones and serum 25(OH)D levels are at their nadir [42, 43]. In a nested case-control study by Bodnar et al. [44], pregnant women were followed from less than 16week gestation to delivery at prenatal clinics and private practices. Patients included nulliparous pregnant women with singleton pregnancies only. Adjusted serum 25(OH)D concentrations in early pregnancy were 15\% lower in women who subsequently developed preeclampsia compared to controls. Early-pregnancy maternal $25(\mathrm{OH}) \mathrm{D}$ concentration less than $37.5 \mathrm{nmol} / \mathrm{L}$ was associated with a 5fold increase in the odds of preeclampsia, independent of race/ethnicity, season, gestational age, prepregnancy BMI, and education. After confounder adjustment, a $50-\mathrm{nmol} / \mathrm{L}$ decline in $25(\mathrm{OH}) \mathrm{D}$ concentration doubled the risk of preeclampsia. Findings of this study indicate that maternal vitamin D deficiency may be an independent risk factor for preeclampsia.

Very recently, Bills et al. reported that low plasma vascular endothelial growth factor (VEGF) in the first trimester is a predictive marker for preeclampsia [45]. On the other hand, Cardus et al. found that $1,25(\mathrm{OH}) 2$ vitamin $D$ regulates VEGF production through a vitamin D response element in the VEGF promoter [46]. Thus, lack of vitamin D may have a role in pathogenesis of developing hypertension via decreased VEGF production. 


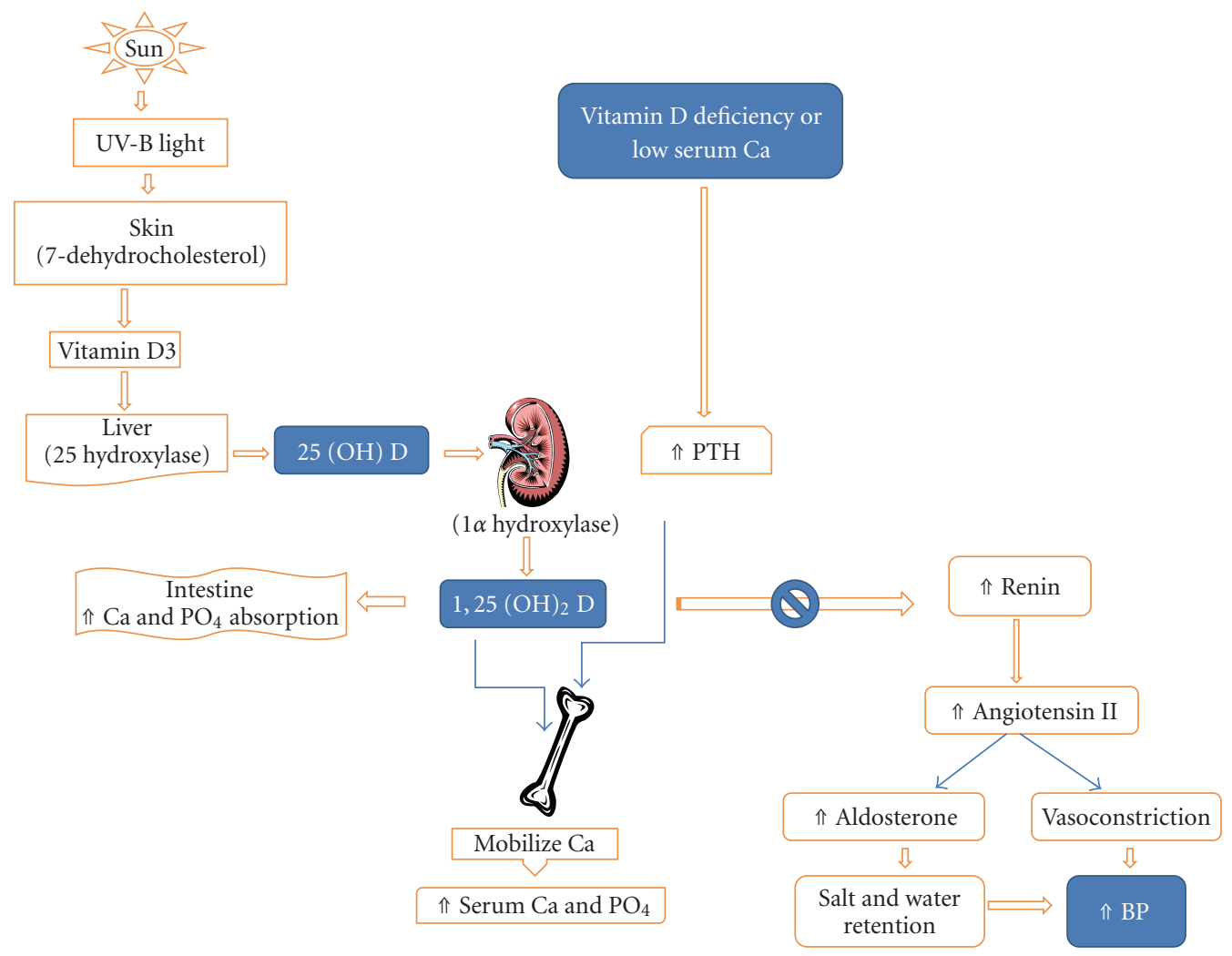

FIGURE 1: Pathway of vitamin D metabolism and its relationship with PTH and renin-angiotensin-aldosterone system.

\section{Vitamin D Deficiency and Hypertension: Potential Biological Mechanisms}

9.1. Regulation of the Renin Angiotensin System (RAS). The renin angiotensin system (RAS) is a regulatory cascade that plays a critical role in the regulation of blood pressure, electrolyte, and plasma volume homeostasis. Inappropriate stimulation of the RAS has been associated with hypertension. $\mathrm{Li}$ et al. [10] demonstrated that vitamin $\mathrm{D}$ is a potent endocrine suppressor of renin biosynthesis to regulate the RAS. Mice lacking vitamin D receptor (VDR) have elevated production of renin and angiotensin II, leading to hypertension, cardiac hypertrophy, and increased water intake. These abnormalities can be prevented by treatment with an $\mathrm{ACE}$ inhibitor or $\mathrm{AT}_{1}$ receptor antagonist. Vitamin $\mathrm{D}$ suppression of renin expression is independent of calcium metabolism, the volume and salt-sensing mechanisms, and the angiotensin II feedback regulation. In normal mice, vitamin D deficiency stimulates renin expression, whereas injection of 1,25-dihydroxyvitamin $\mathrm{D}_{3}\left[1,25(\mathrm{OH})_{2} \mathrm{D}_{3}\right]$ reduces renin synthesis. In cell cultures, $1,25(\mathrm{OH})_{2} \mathrm{D}$ directly suppresses renin gene transcription by a VDR-dependent mechanism. Thus, vitamin D-deficiency may increase the risk of hypertension, and vitamin $\mathrm{D}$ supplementation may be beneficial to the cardiovascular system. In a transgenic mouse model with mice over-expressing the human vitamin D receptor in renin-producing cells, Kong et al. demonstrated that suppression of renin expression by $1,25(\mathrm{OH})_{2} \mathrm{D}$ in vivo is independent of parathyroid hormone and calcium [47] (see Figure 1).

9.2. Relationship of Parathyroid Hormone with Hypertension in Primary and Secondary Hyperparathyroidism. Vitamin $\mathrm{D}$ deficiency is prevalent in patients with primary hyperparathyroidism (HPT) [48-50]. Primary HPT with an inappropriately elevated PTH level has been shown to be associated with hypertension (in up to $40 \%$ of cases) but the mechanism of developing hypertension has remained controversial. Low vitamin D status is associated with secondary elevation of PTH as well as increased arterial resistance leading to hypertension [51]. It has also been implicated directly and indirectly to affect cardiovascular risk by increasing susceptibility to arterial calcification [52]. The patients with mild primary HPT have been found to have increased stiffness measured in the radial artery [53]. In both primary and secondary hyperparathyroidism, elevated PTH levels may contribute to elevation of blood pressure.

Puepet et al. [54] reported a 47-year-old Nigerian man with severe hypertension (BP 210/130 mm Hg) and primary hyperparathyroidism who had a normal blood pressure after parathyroidectomy. Gennari et al. [55] studied patients with primary hyperparathyroidism with parathyroid adenoma and observed that plasma renin activity, and plasma aldosterone levels were higher among these patients who were hypertensive and the blood pressure, plasma renin activity and plasma aldosterone levels became normal 
after parathyroidectomy in most of them. These results are consistent with the hypothesis of a possible direct effect of PTH on renin secretion, which could contribute to the pathogenesis of hypertension. However, there are contradictory results as well. Bollerslev et al. studied the effect of parathyroidectomy on cardiovascular risk factors in patients with mild primary hyperparathyroidism and found no significant differences between the groups for blood pressure or markers of insulin resistance [56]. On the other hand, Rydberg et al. [57] found increased blood pressure values after parathyroidectomy in patients with primary hyperparathyroidism and a history of hypertension. Jorde et al. found that serum PTH was a significant predictor of rise in systolic blood pressure over a period of 7 years in men $(P<.01)$, but not in women [58]. Fardella and RodriguezPortales observed a positive correlation between PTH and intracellular calcium and suggested that PTH may act as an ionophore for calcium entry into cells and perhaps react a prehypertensive condition in normotensive patients with primary hyperparathyroidism [59].

9.3. Vitamin D Deficiency, Obesity, and Insulin Resistance. An association of obesity with low serum vitamin D levels has been reported. Physical inactivity including decreased outdoor activities may lead to diminished exposure to ultraviolet light. This may partly account for the lower level of serum vitamin D in overweight and obese participants, who are more likely to be sedentary in their lifestyle. Analyzing the NHANES III data, Scragg and Camargo Jr. reported a 25 percent reduction in the prevalence in the vitamin $\mathrm{D}$ deficiency among the study population who had increased outdoor physical activities in the previous month prior to data collection [60]. In addition, the lipid solubility of vitamin D also modifies its bioavailability due to sequestration in the adipose tissue and may contribute to the lower serum levels of vitamin D in overweight and obese persons [61]. There are some observational and case-control studies suggesting that hypovitaminosis $\mathrm{D}$ is associated with decreased insulin secretion [62] and that vitamin D supplementation reduces the concentrations of free fatty acids in diabetics, thereby improving insulin sensitivity [63]. There is a high prevalence of type 2 diabetes and insulin resistance in patients with primary hyperparathyroidism which could aggravate hypertension and inflammation, further contributing to the cardiovascular risk in these patients $[64,65]$. In a prospective study by Ahlström, PTH correlated with several metabolic factors within a normocalcemic study population and individuals with mild primary HPT had significantly more NCEP criteria for the metabolic syndrome [66].

Scragg et al. reported hypovitaminosis D being associated with higher insulin resistance and increased risk of diabetes $[67,68]$. Pittas et al. prospectively evaluated the effect of vitamin D supplementation (400 IU per day) on fasting glucose which improved after a 3-year period of therapy when compared to subjects on placebo [69]. In a Framingham Offspring study involving nondiabetic individuals, a strong inverse correlation between serum vitamin D concentrations and fasting plasma glucose as well as fasting insulin levels was found, after adjustment for age, gender, BMI, waist circumference, and smoking [70]. In another cross-sectional study involving hemodialysis patients [71], low serum vitamin D was independently associated with diabetes mellitus, higher brain natriuretic peptide levels, higher pulse pressure, and higher vascular calcification scores.

Resnick and colleagues espouse an "ionic"-based theory for the onset and development of hypertension, type 2 diabetes, obesity, and other manifestations of the metabolic syndrome that is characterized by elevated intracellular calcium, reduced intracellular magnesium, and reduced intracellular $\mathrm{pH}$ [72-76]. Intracellular calcium appears to have a biphasic effect on the differentiation of preadipocytes to adipocytes. Low serum calcium resulting from low dietary intake or vitamin D deficiency leads to secondary elevation of PTH which, in turn, causes increased intracellular calcium [77] that leads to increased differentiation of preadipocytes to adipocytes [78]. It also inhibits GLUT-4 function impeding insulin mediated glucose uptake [79]. On the other hand, increased dietary calcium appears to be associated with inhibition of serum 1,25 hydroxy vitamin $\mathrm{D}$ which results in decreased intracellular calcium levels and thus decreased adipogenesis $[80,81]$. There is also accumulating evidence suggesting that increased intracellular calcium has stimulating effect on adipocyte 11-beta hydroxysteroid dehydrogenase (HSD) type 1 activity similar to angiotensin 2, leading to increased cortisol production in adipocytes [82]. Among other means, this appears to be a membrane-mediated (rather than nuclear receptor mediated) effect of 1,25 hydroxy vitamin D which can be inhibited by an angiotensin receptor blocker (see Figures 2(a), 2(b)).

9.4. Vitamin D Deficiency, Calcium, and Endothelial Function. Hypovitaminosis D has been shown to have direct effects on the vasculature causing increased vascular resistance [83]. It is also independently associated with increased carotid intima-media thickness [84] and decreased arterial compliance [85]. Sugden et al. found that endothelial function (as assessed by flow-mediated dilation) and blood pressure improved in diabetics who ingested a single dose of vitamin D (100 $000 \mathrm{IU})$ [86]. Ekmekci et al. [87] reported that elevated serum calcium and parathyroid hormone levels were independent predictors of impaired endothelial function and endothelial nitric oxide polymorphism (eNOS), which is often associated with coronary artery disease, and hypertension, did not appear to have modifying effect on the endothelial function in his study.

\section{Conclusions}

Evidence from clinical and epidemiological studies support a possible relationship between low vitamin $\mathrm{D}$ level and hypertension, and there are some plausible biological mechanisms as well. However, epidemiological studies are always vulnerable to multiple confounding factors that cannot be always controlled. The unique and complex interactions between hypovitaminosis D, parathyroid hormone, and calcium (both in the serum and in intracellular compartments) 


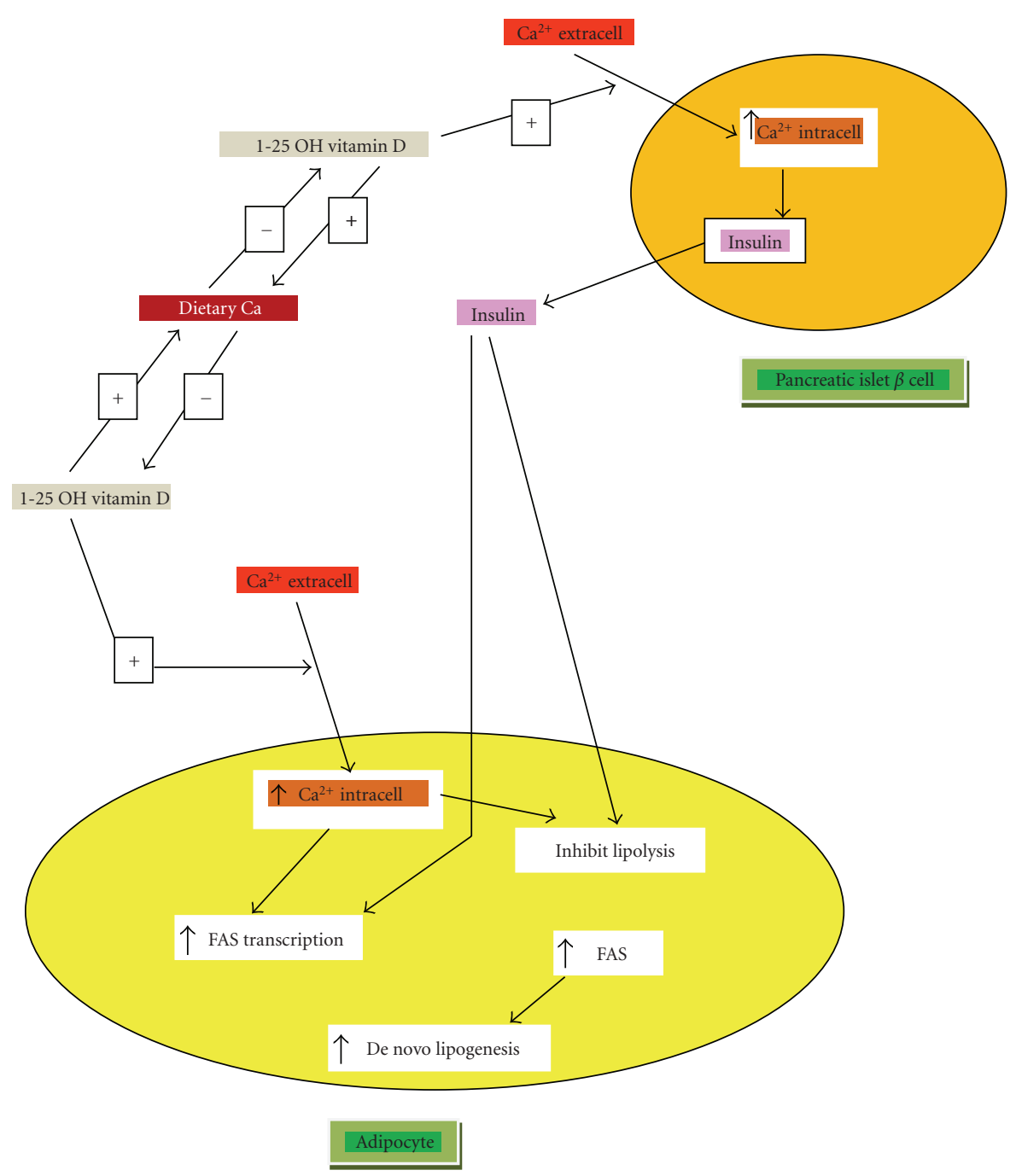

(a)

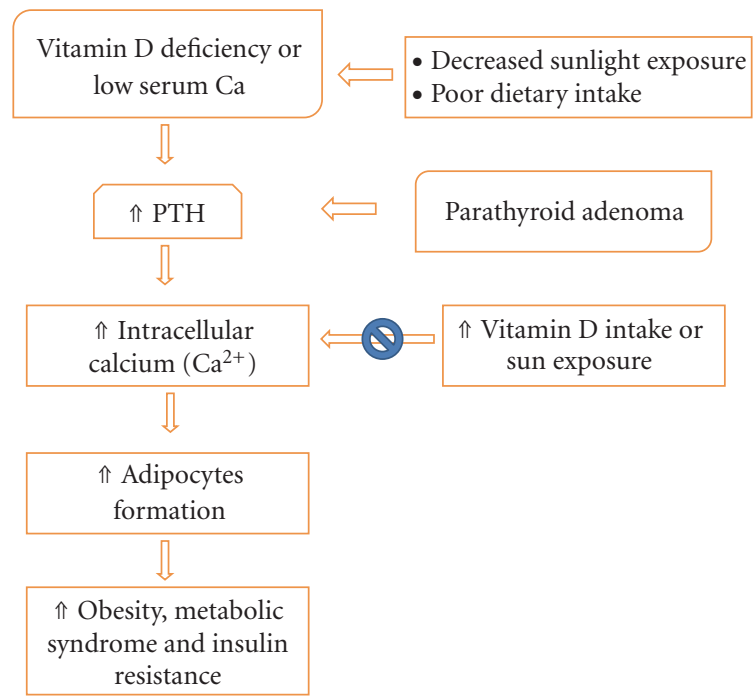

(b)

Figure 2: (a) Dietary and intracellular calcium + vitamin D modulation of adiposity. (b) Complex relationship between vitamin D, parathyroid hormone, intracellular calcium, and adipocyte formation. 
make it especially difficult to tease apart how much of these effects are truly unique and distinct to vitamin D. Moreover, statistically significant associations between two factors do not prove that one has been the causative factor for the other, as these two factors may be closely related to a third factor. In this case, a low vitamin D level may merely be a surrogate for the lack of outdoor physical activity. Outdoor physical inactivity itself may precipitate hypertension as well as leading to a cascade of events (including low sun-exposure and vitamin D deficiency, obesity, metabolic syndrome, and increased insulin resistance), all of which may cause or aggravate hypertension. The problems with bias and confounding factors may be overcome or minimized by welldesigned randomized controlled trials.

Results of recent interventional studies that investigated the potential benefit of vitamin D supplementation on blood pressure have not been promising. Further studies are needed to find out if and when vitamin D supplementation should be used for treating patients with hypertension. It is apparent that vitamin D supplementation may be appropriate for populations that are most vulnerable to hypovitaminosis $\mathrm{D}$. But it is not clear what degree of vitamin D deficiency may activate the renin-angiotensin system (RAS) and trigger an increase in blood pressure. Most recent studies investigating the association of health conditions related to vitamin $\mathrm{D}$ suggest that a desirable $25(\mathrm{OH}) \mathrm{D}$ concentration may be at least $30 \mathrm{ng} / \mathrm{mL}(75 \mathrm{nmol} / \mathrm{L}$ ) (but less than $100 \mathrm{ng} / \mathrm{mL}$ ) for optimum health; yet no consensus has been reached about its cut-off level [88-90]. This already represents a limiting factor in future studies, as each individual likely has a different cut-off, depending on ethnic group and/or polymorphisms in the vitamin $\mathrm{D}$ receptor and its promoter which mediates vitamin $\mathrm{D}$ action. Therefore, more comprehensive studies may be needed including genetic profiling of study subjects with various levels of serum vitamin $\mathrm{D}$ to see what is the most likely cutoff level that triggers clinical hypertension. The challenge remains that hypertension is multifactorial and some individuals with other comorbidities (like smoking, obesity, physical inactivity, metabolic syndrome) may have a lower threshold for vitamin D deficiency induced clinical hypertension compared to those who donot have these risk factors.

Because of the increasing evidence in favor of an association between vitamin D deficiency and cardiovascular diseases, it may be prudent to screen and correct hypovitaminosis D in high-risk patients such as those with resistant hypertension, nursing home residents, osteoporotic individuals, pregnant women in areas where the incidence of toxemia of pregnancy is high (south-east Asia), African Americans, and the female population in some geographic/religious groups where covering the entire body with clothing is customary. If screening is not available, supplementation with vitamin D 1000-2000 IU daily among this subpopulation may be safe and appropriate [91-93]. This can easily be achieved as vitamin D is available over the counter and is unlikely to cause any toxicity at this dosage. Finally, studies are underway to find vitamin D analogs with minimal calcemic potential but greater activity on RAS modulation. This may open a new horizon for a group of therapeutic inhibitors of the RAS and potentially offer a new class of antihypertensive drugs that may be used in hypertensive individuals with or without vitamin D deficiency.

\section{References}

[1] M. S. Calvo, S. J. Whiting, and C. N. Barton, "Vitamin D intake: a global perspective of current status," The Journal of Nutrition, vol. 135, no. 2, pp. 310-316, 2005.

[2] S. E. Judd and V. Tangpricha, "Vitamin D deficiency and risk for cardiovascular disease," The American Journal of the Medical Sciences, vol. 338, no. 1, pp. 40-44, 2009.

[3] M. F. Holick, "Medical progress: vitamin D deficiency," The New England Journal of Medicine, vol. 357, no. 3, pp. 266-281, 2007.

[4] B. G. Druss, S. C. Marcus, M. Olfson, T. Tanielian, L. Elinson, and H. A. Pincus, "Comparing the national economic burden of five chronic conditions," Health Affairs, vol. 20, no. 6, pp. 233-241, 2001.

[5] T. L. Clemens, J. S. Adams, S. L. Henderson, and M. F. Holick, "Increased skin pigment reduces the capacity of skin to synthesise vitamin D3," The Lancet, vol. 1, no. 8263, pp. 7476, 1982.

[6] H. F. DeLuca, "Overview of general physiologic features and functions of vitamin D," The American Journal of Clinical Nutrition, vol. 80, no. 6, pp. 1689S-1696S, 2004.

[7] M. F. Holick and M. Garabedian, "Vitamin D: photobiology, metabolism((30)), mechanism of action, and clinical applications," in Primer on the Metabolic Bone Diseases and Disorders of Mineral Metabolism, M. J. Favus, Ed., vol. 4, pp. 129-137, American Society for Bone and Mineral Research, Washington, DC, USA, 6th edition, 2006.

[8] M. F. Holick, "Sunlight and vitamin D for bone health and prevention of autoimmune diseases, cancers, and cardiovascular disease," The American Journal of Clinical Nutrition, vol. 80, no. 6, pp. 1678S-1688S, 2004.

[9] M. F. Holick, "Vitamin D: a millennium perspective," Journal of Cellular Biochemistry, vol. 88, pp. 296-307, 2003.

[10] Y. C. Li, G. Qiao, M. Uskokovic, W. Xiang, W. Zheng, and J. Kong, "Vitamin D: a negative endocrine regulator of the reninangiotensin system and blood pressure," Journal of Steroid Biochemistry and Molecular Biology, vol. 89-90, pp. 387-392, 2004.

[11] Y. C. Li, J. Kong, M. Wei, Z.-F. Chen, S. Q. Liu, and L.P. Cao, "1,25-Dihydroxyvitamin D3 is a negative endocrine regulator of the renin-angiotensin system," The Journal of Clinical Investigation, vol. 110, no. 2, pp. 229-238, 2002.

[12] Intersalt Cooperative Research Group, "Intersalt: an international study of electrolyte excretion and blood pressure. Results for 24 hour urinary sodium and potassium excretion," British Medical Journal, vol. 297, no. 6644, pp. 319-328, 1988.

[13] S. G. Rostand, "Ultraviolet light may contribute to geographic and racial blood pressure differences," Hypertension, vol. 30, no. 2, pp. 150-156, 1997.

[14] Z. Lu, T. C. Chen, L. Kline, et al., "Photosynthesis of previtamin D1 in cities around the world," in Proceedings of the Biologic Effects of Light Symposium, M. F. Holick and A. Kligman, Eds., pp. 48-52, Walter de Gruyter, Berlin, Germany, 1992.

[15] M. F. Holick, "McCollum award lecture, 1994: vitamin Dnew horizons for the 21st century," The American Journal of Clinical Nutrition, vol. 60, no. 4, pp. 619-630, 1994. 
[16] M. F. Holick, "High prevalence of vitamin D inadequacy and implications for health," Mayo Clinic Proceedings, vol. 81, no. 3, pp. 353-373, 2006.

[17] D. A. McCarron, P. A. Pingree, R. J. Rubin, S. M. Gaucher, M. Molitch, and S. Krutzik, "Enhanced parathyroid function in essential hypertension: a homeostatic response to a urinary calcium leak," Hypertension, vol. 2, no. 2, pp. 162-168, 1980.

[18] R. Cooper and C. Rotimi, "Hypertension in populations of West African origin: is there a genetic predisposition?" Journal of Hypertension, vol. 12, no. 3, pp. 215-227, 1994.

[19] H. G. Langford and R. L. Watson, "Potassium and calcium intake, excretion, and homeostasis in blacks, and their relation to blood pressure," Cardiovascular Drugs and Therapy, vol. 4, supplement 2, pp. 403-406, 1990.

[20] M. B. Zemel, P. C. Zemel, R. J. Bryg, and J. R. Sowers, "Dietary calcium induces regression of left ventricular hypertrophy in hypertensive non-insulin-dependent diabetic blacks," American Journal of Hypertension, vol. 3, no. 6, pp. 458-463, 1990.

[21] M. B. Zemel, S. M. Gualdoni, and J. R. Sowers, "Reductions in total and extracellular water associated with calciuminduced natriuresis and the antihypertensive effect of calcium in blacks," American Journal of Hypertension, vol. 1, no. 1, pp. 70-72, 1988.

[22] L. E. Griffith, G. H. Guyatt, R. J. Cook, H. C. Bucher, and D. J. Cook, "The influence of dietary and nondietary calcium supplementation on blood pressure: an updated metaanalysis of randomized controlled trials," American Journal of Hypertension, vol. 12, no. 1, pp. 84-92, 1999.

[23] P. S. Allender, J. A. Cutler, D. Follmann, F. P. Cappuccio, J. Pryer, and P. Elliott, "Dietary calcium and blood pressure: a meta-analysis of randomized clinical trials," Annals of Internal Medicine, vol. 124, no. 9, pp. 825-831, 1996.

[24] R. Scragg, M. Sowers, and C. Bell, "Serum 25-hydroxyvitamin D, ethnicity, and blood pressure in the Third National Health and Nutrition Examination Survey," American Journal of Hypertension, vol. 20, no. 7, pp. 713-719, 2007.

[25] S. E. Judd, M. S. Nanes, T. R. Ziegler, P. W. F. Wilson, and V. Tangpricha, "Optimal vitamin D status attenuates the age-associated increase in systolic blood pressure in white Americans: results from the Third National Health and Nutrition Examination Survey," The American Journal of Clinical Nutrition, vol. 87, no. 1, pp. 136-141, 2008.

[26] D. Martins, M. Wolf, D. Pan, et al., "Prevalence of cardiovascular risk factors and the serum levels of 25-hydroxyvitamin D in the United States: data from the Third National Health and Nutrition Examination Survey," Archives of Internal Medicine, vol. 167, no. 11, pp. 1159-1165, 2007.

[27] J. P. Forman, E. Giovannucci, M. D. Holmes, et al., "Plasma 25hydroxyvitamin D levels and risk of incident hypertension," Hypertension, vol. 49, no. 5, pp. 1063-1069, 2007.

[28] R. Krause, M. Buhring, W. Hopfenmuller, M. F. Holick, and A. M. Sharma, "Ultraviolet B and blood pressure," The Lancet, vol. 352, no. 9129, pp. 709-710, 1998.

[29] M. Pfeifer, B. Begerow, H. W. Minne, D. Nachtigall, and C. Hansen, "Effects of a short-term vitamin D3 and calcium supplementation on blood pressure and parathyroid hormone levels in elderly women," The Journal of Clinical Endocrinology \& Metabolism, vol. 86, no. 4, pp. 1633-1637, 2001.

[30] J. P. Forman, H. A. Bischoff-Ferrari, W. C. Willett, M. J. Stampfer, and G. C. Curhan, "Vitamin D intake and risk of incident hypertension: results from three large prospective cohort studies," Hypertension, vol. 46, no. 4, pp. 676-682, 2005.
[31] K. L. Margolis, R. M. Ray, L. Van Horn, et al., "Effect of calcium and vitamin D supplementation on blood pressure: the women's health initiative randomized trial," Hypertension, vol. 52, no. 5, pp. 847-855, 2008.

[32] E. S. Orwoll and S. Oviatt, "Relationship of mineral metabolism and long-term calcium and cholecalciferol supplementation to blood pressure in normotensive men," The American Journal of Clinical Nutrition, vol. 52, no. 4, pp. 717$721,1990$.

[33] R. Scragg, K.-T. Khaw, and S. Murphy, "Effect of winter oral vitamin D3 supplementation on cardiovascular risk factors in elderly adults," European Journal of Clinical Nutrition, vol. 49, no. 9, pp. 640-646, 1995.

[34] M. B. Snijder, P. Lips, J. C. Seidell, et al., "Vitamin D status and parathyroid hormone levels in relation to blood pressure: a population-based study in older men and women," Journal of Internal Medicine, vol. 261, no. 6, pp. 558-565, 2007.

[35] B. Hintzpeter, G. B. M. Mensink, W. Thierfelder, M. J. Müller, and C. Scheidt-Nave, "Vitamin D status and health correlates among German adults," European Journal of Clinical Nutrition, vol. 62, no. 9, pp. 1079-1089, 2008.

[36] J. M. Geleijnse, "Vitamin D and hypertension: does the women's health initiative solve the question?" Hypertension, vol. 52, no. 5, pp. 803-804, 2008.

[37] J. M. Lappe, D. Travers-Gustafson, K. M. Davies, R. R. Recker, and R. P. Heaney, "Vitamin D and calcium supplementation reduces cancer risk: results of a randomized trial," The American Journal of Clinical Nutrition, vol. 85, no. 6, pp. 15861591, 2007.

[38] J. MacLaughlin and M. F. Holick, "Aging decreases the capacity of human skin to produce vitamin D3," The Journal of Clinical Investigation, vol. 76, no. 4, pp. 1536-1538, 1985.

[39] L. M. Bodnar, H. N. Simhan, R. W. Powers, M. P. Frank, E. Cooperstein, and J. M. Roberts, "High prevalence of vitamin $\mathrm{D}$ insufficiency in black and white pregnant women residing in the northern United States and their neonates," The Journal of Nutrition, vol. 137, no. 2, pp. 447-452, 2007.

[40] B. Eskenazi, L. Fenster, and S. Sidney, "A multivariate analysis of risk factors for preeclampsia," The Journal of the American Medical Association, vol. 266, no. 2, pp. 237-241, 1991.

[41] E. Hyppönen, A.-L. Hartikainen, U. Sovio, M.-R. Järvelin, and A. Pouta, "Does vitamin D supplementation in infancy reduce the risk of pre-eclampsia?" European Journal of Clinical Nutrition, vol. 61, no. 9, pp. 1136-1139, 2007.

[42] L. M. Bodnar, J. M. Catov, and J. M. Roberts, "Racial/ethnic differences in the monthly variation of preeclampsia incidence," American Journal of Obstetrics and Gynecology, vol. 196, no. 4, pp. 324.e1-324.e5, 2007.

[43] P. Magnus and A. Eskild, "Seasonal variation in the occurrence of pre-eclampsia," British Journal of Obstetrics and Gynaecology, vol. 108, no. 11, pp. 1116-1119, 2001.

[44] L. M. Bodnar, J. M. Catov, H. N. Simhan, M. F. Holick, R. W. Powers, and J. M. Roberts, "Maternal vitamin D deficiency increases the risk of preeclampsia," The Journal of Clinical Endocrinology \& Metabolism, vol. 92, no. 9, pp. 3517-3522, 2007.

[45] V. L. Bills, J. Varet, A. Millar, S. J. Harper, P. W. Soothill, and D. O. Bates, "Failure to up-regulate VEGF ${ }_{165}$ b in maternal plasma is a first trimester predictive marker for pre-eclampsia," Clinical Science, vol. 116, no. 3, pp. 265-272, 2009.

[46] A. Cardus, S. Panizo, M. Encinas, et al., "1,25Dihydroxyvitamin D3 regulates VEGF production through a vitamin D response element in the VEGF promoter," Atherosclerosis, vol. 204, no. 1, pp. 85-89, 2009. 
[47] J. Kong, G. Qiao, Z. Zhang, S. Q. Liu, and Y. C. Li, "Targeted vitamin D receptor expression in juxtaglomerular cells suppresses renin expression independent of parathyroid hormone and calcium," Kidney International, vol. 74, no. 12, pp. 1577-1581, 2008.

[48] A. Grey, J. Lucas, A. Horne, G. Gamble, J. S. Davidson, and I. R. Reid, "Vitamin D repletion in patients with primary hyperparathyroidism and coexistent vitamin D insufficiency," The Journal of Clinical Endocrinology \& Metabolism, vol. 90, no. 4, pp. 2122-2126, 2005.

[49] S. Silverberg, "Vitamin D deficiency and primary hyperparathyroidism," Journal of Bone and Mineral Research, vol. 22, supplement 2, pp. V100-V104, 2007.

[50] E. G. Grubbs, S. Rafeeq, C. Jimenez, et al., "Preoperative vitamin $\mathrm{D}$ replacement therapy in primary hyperparathyroidismml: safe and beneficial?” Surgery, vol. 144, no. 6, pp. 852-859, 2008.

[51] P. N. Sambrook, C. J. S. Chen, L. March, et al., "High bone turnover is an independent predictor of mortality in the frail elderly," Journal of Bone and Mineral Research, vol. 21, no. 4, pp. 549-555, 2006.

[52] K. E. Watson, M. L. Abrolat, L. L. Malone, et al., "Active serum vitamin D levels are inversely correlated with coronary calcification," Circulation, vol. 96, no. 6, pp. 1755-1760, 1997.

[53] M. R. Rubin, M. S. Maurer, D. J. McMahon, J. P. Bilezikian, and S. J. Silverberg, "Arterial stiffness in mild primary hyperparathyroidism," The Journal of Clinical Endocrinology \& Metabolism, vol. 90, no. 6, pp. 3326-3330, 2005.

[54] F. H. Puepet, E. I. Agaba, E. K. Chuhwak, and S. O. Ugoya, "Primary hyperparathyroidism presenting with severe hypertension in a middle aged Nigerian-a case report," The Nigerian Postgraduate Medical Journal, vol. 15, no. 1, pp. 5860, 2008.

[55] C. Gennari, R. Nami, and S. Gonnelli, "Hypertension and primary hyperparathyroidismml: the role of adrenergic and renin-angiotensin-aldosterone systems," Mineral and Electrolyte Metabolism, vol. 21, no. 1-3, pp. 77-81, 1995.

[56] J. Bollerslev, T. Rosen, C. L. Mollerup, et al., "Effect of surgery on cardiovascular risk factors in mild primary hyperparathyroidism," The Journal of Clinical Endocrinology \& Metabolism, vol. 94, no. 7, pp. 2255-2261, 2009.

[57] E. Rydberg, M. Birgander, A.-G. Bondeson, L. Bondeson, and R. Willenheimer, "Effect of successful parathyroidectomy on 24-hour ambulatory blood pressure in patients with primary hyperparathyroidism," International Journal of Cardiology. In press.

[58] R. Jorde, J. Svartberg, and J. Sundsfjord, "Serum parathyroid hormone as a predictor of increase in systolic blood pressure in men," Journal of Hypertension, vol. 23, no. 9, pp. 1639-1644, 2005.

[59] C. Fardella and J. A. Rodriguez-Portales, "Intracellular calcium and blood pressure: comparison between primary hyperparathyroidism and essential hypertension," Journal of Endocrinological Investigation, vol. 18, no. 11, pp. 827-832, 1995.

[60] R. Scragg and C. A. Camargo Jr., "Scragg and camargo respond to "physical activity and vitamin D"', American Journal of Epidemiology, vol. 168, no. 6, pp. 590-591, 2008.

[61] S. J. Parikh, M. Edelman, G. I. Uwaifo, R. J. Freedman, M. Semega-Janneh, J. Reynolds, and J. A. Yanovski, "The relationship between obesity and serum 1,25-dihydroxy vitamin D concentrations in healthy adults," The Journal of Clinical Endocrinology \& Metabolism, vol. 89, no. 3, pp. 1196-1199, 2004.
[62] A. W. Norman, B. J. Frankel, A. M. Heldt, and G. M. Grodsky, "Vitamin D deficiency inhibits pancreatic secretion of insulin," Science, vol. 209, no. 4458, pp. 823-825, 1980.

[63] G. Rammos, P. Tseke, and S. Ziakka, "Vitamin D, the reninangiotensin system, and insulin resistance," International Urology and Nephrology, vol. 40, no. 2, pp. 419-426, 2008.

[64] W. H. Taylor, "The prevalence of diabetes mellitus in patients with primary hyperparathyroidism and among their relatives," Diabetic Medicine, vol. 8, no. 7, pp. 683-687, 1991.

[65] A. Kautzky-Willer, G. Pacini, B. Niederle, G. Schernthaner, and R. Prager, "Insulin secretion, insulin sensitivity and hepatic insulin extraction in primary hyperparathyroidism before and after surgery," Clinical Endocrinology, vol. 37, no. 2, pp. 147-155, 1992.

[66] T. Ahlström, E. Hagström, A. Larsson, C. Rudberg, L. Lind, and P. Hellman, "Correlation between plasma calcium, parathyroid hormone (PTH) and the metabolic syndrome (MetS) in a community-based cohort of men and women," Clinical Endocrinology, vol. 71, no. 5, pp. 673-678, 2009.

[67] R. Scragg, M. Sowers, and C. Bell, "Serum 25-hydroxyvitamin D, diabetes, and ethnicity in the Third National Health and Nutrition Examination Survey," Diabetes Care, vol. 27, no. 12, pp. 2813-2818, 2004.

[68] M. Chonchol and R. Scragg, "25-hydroxyvitamin D, insulin resistance, and kidney function in the Third National Health and Nutrition Examination Survey," Kidney International, vol. 71, no. 2, pp. 134-139, 2007.

[69] A. G. Pittas, S. S. Harris, P. C. Stark, and B. Dawson-Hughes, "The effects of calcium and vitamin D supplementation on blood glucose and markers of inflammation in nondiabetic adults," Diabetes Care, vol. 30, no. 4, pp. 980-986, 2007.

[70] E. Liu, J. B. Meigs, A. G. Pittas, et al., "Plasma 25hydroxyvitamin $\mathrm{D}$ is associated with markers of the insulin resistant phenotype in nondiabetic adults," The Journal of Nutrition, vol. 139, no. 2, pp. 329-334, 2009.

[71] P. J. Matias, C. Ferreira, C. Jorge, et al., "25-hydroxyvitamin D3, arterial calcifications and cardiovascular risk markers in haemodialysis patients," Nephrology Dialysis Transplantation, vol. 24, no. 2, pp. 611-618, 2009.

[72] L. M. Resnick, "Calcium metabolism in hypertension and allied metabolic disorders," Diabetes Care, vol. 14, no. 6, pp. 505-520, 1991.

[73] L. M. Resnick, R. K. Gupta, K. K. Bhargava, H. Gruenspan, M. H. Alderman, and J. H. Laragh, "Cellular ions in hypertension, diabetes, and obesity: a nuclear magnetic resonance spectroscopic study," Hypertension, vol. 17, no. 6, part 2, pp. 951-957, 1991.

[74] V. Petrov and P. Lijnen, "Modification of intracellular calcium and plasma renin by dietary calcium in men," American Journal of Hypertension, vol. 12, no. 12, part 1-2, pp. 12171224, 1999.

[75] L. Resnick, "The cellular ionic basis of hypertension and allied clinical conditions," Progress in Cardiovascular Diseases, vol. 42, no. 1, pp. 1-22, 1999.

[76] L. M. Resnick, "Cellular calcium and magnesium metabolism in the pathophysiology and treatment of hypertension and related metabolic disorders," The American Journal of Medicine, vol. 93, no. 2A, pp. 11S-20S, 1992.

[77] G. Kamalov, J. P. Holewinski, S. K. Bhattacharya, et al., "Nutrient dyshomeostasis in congestive heart failure," The American Journal of the Medical Sciences, vol. 338, no. 1, pp. 28-33, 2009.

[78] H. Shi, Y. D. Halvorsen, P. N. Ellis, W. O. Wilkison, and M. B. Zemel, "Role of intracellular calcium in human adipocyte 
differentiation," Physiol Genomics, vol. 3, no. 2, pp. 75-82, 2000.

[79] N. Begum, W. Leitner, J. E.-B. Reusch, K. E. Sussman, and B. Draznin, "GLUT-4 phosphorylation and its intrinsic activity. Mechanism of $\mathrm{Ca}^{2+}$ - induced inhibition of insulin-stimulated glucose transport," Journal of Biological Chemistry, vol. 268, no. 5, pp. 3352-3356, 1993.

[80] M. B. Zemel, "Mechanisms of dairy modulation of adiposity," The Journal of Nutrition, vol. 133, no. 1, pp. 252S-256S, 2003.

[81] M. B. Zemel, H. Shi, B. Greer, D. Dirienzo, and P. C. Zemel, "Regulation of adiposity by dietary calcium," FASEB Journal, vol. 14, no. 9, pp. 1132-1138, 2000.

[82] M. B. Zemel and T. Sobhani, "Intracellular calcium modulation of cortisol production in human adipocytes," FASEB Journal, vol. 17, p. A323, 2003.

[83] D. Duprez, M. De Buyzere, T. De Backer, and D. Clement, "Relationship between vitamin D and the regional blood flow and vascular resistance in moderate arterial hypertension," Journal of Hypertension, vol. 11, pp. S304-S305, 1993.

[84] G. Targher, L. Bertolini, R. Padovani, et al., "Serum 25hydroxyvitamin D3 concentrations and carotid artery intimamedia thickness among type 2 diabetic patients," Clinical Endocrinology, vol. 65, no. 5, pp. 593-597, 2006.

[85] G. M. London, A. P. Guérin, F. H. Verbeke, et al., "Mineral metabolism and arterial functions in end-stage renal disease: potential role of 25-hydroxyvitamin D deficiency," Journal of the American Society of Nephrology, vol. 18, no. 2, pp. 613-620, 2007.

[86] J. A. Sugden, J. I. Davies, M. D. Witham, A. D. Morris, and A. D. Struthers, "Vitamin D improves endothelial function in patients with type 2 diabetes mellitus and low vitamin D levels," Diabetic Medicine, vol. 25, no. 3, pp. 320-325, 2008.

[87] A. Ekmekci, N. Abaci, N. C. Ozbey, et al., "Endothelial function and endothelial nitric oxide synthase intron $4 \mathrm{a} / \mathrm{b}$ polymorphism in primary hyperparathyroidism," Journal of Endocrinological Investigation. In press.

[88] H. A. Bischoff-Ferrari, E. Giovannucci, W. C. Willett, T. Dietrich, and B. Dawson-Hughes, "Estimation of optimal serum concentrations of 25-hydroxyvitamin D for multiple health outcomes," The American Journal of Clinical Nutrition, vol. 84, no. 1, pp. 18-28, 2006.

[89] E. Hyppönen and C. Power, "Vitamin D status and glucose homeostasis in the 1958 British birth cohort the role of obesity," Diabetes Care, vol. 29, no. 10, pp. 2244-2246, 2006.

[90] M. Visser, D. J. H. Deeg, M. T. E. Puts, J. C. Seidell, and P. Lips, "Low serum concentrations of 25-hydroxyvitamin D in older persons and the risk of nursing home admission," The American Journal of Clinical Nutrition, vol. 84, no. 3, pp. 616622, 2006.

[91] R. B. Costello, "Vitamin D and health in the 21st century: federal initiatives to advance research," The American Journal of the Medical Sciences, vol. 338, no. 1, pp. 34-39, 2009.

[92] Standing Committee on the Scientific Evaluation of Dietary Reference Intakes, Dietary Reference Intakes: Calcium, Phosphorus, Magnesium, Vitamin D, and Fluoride, Food and Nutrition Board, Institute of Medicine. National Academy Press, Washington, DC, USA, 1997.

[93] J. N. Hathcock, A. Shao, R. Vieth, and R. Heaney, "Risk assessment for vitamin D," The American Journal of Clinical Nutrition, vol. 85, no. 1, pp. 6-18, 2007. 


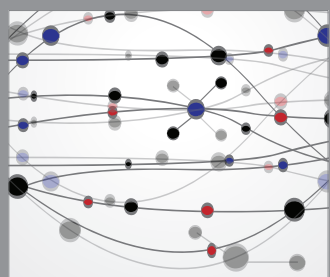

The Scientific World Journal
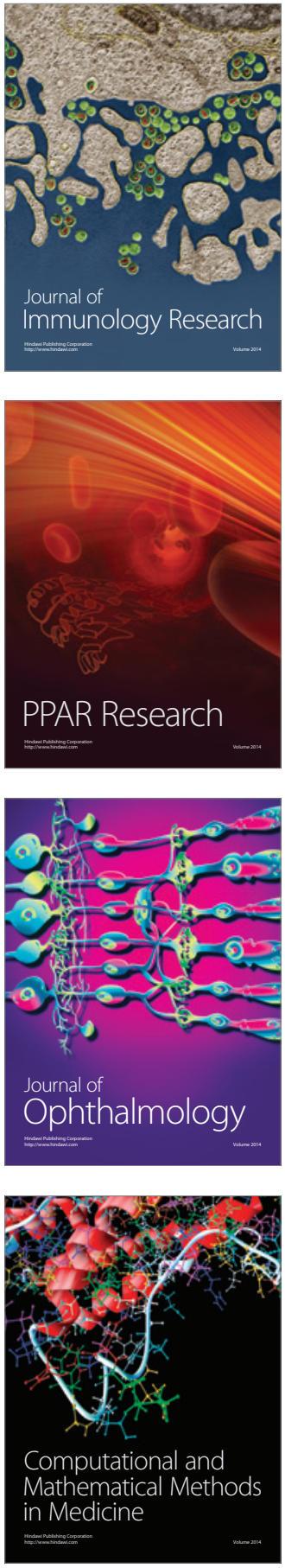

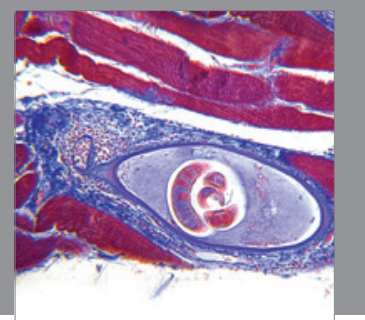

Gastroenterology

Research and Practice
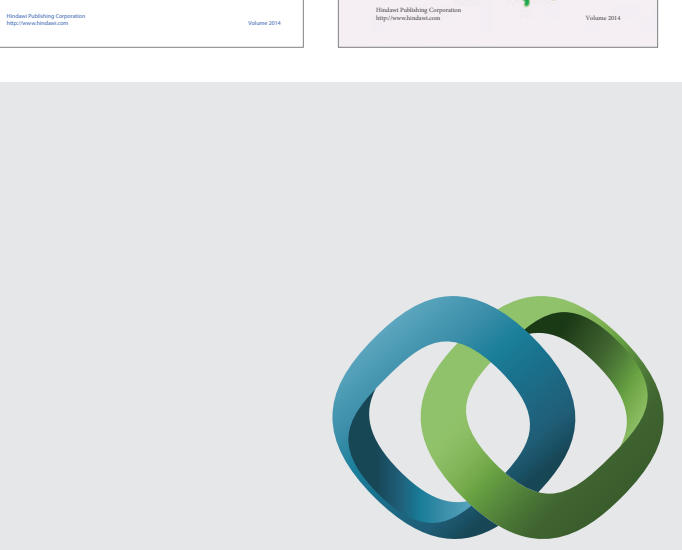

\section{Hindawi}

Submit your manuscripts at

http://www.hindawi.com
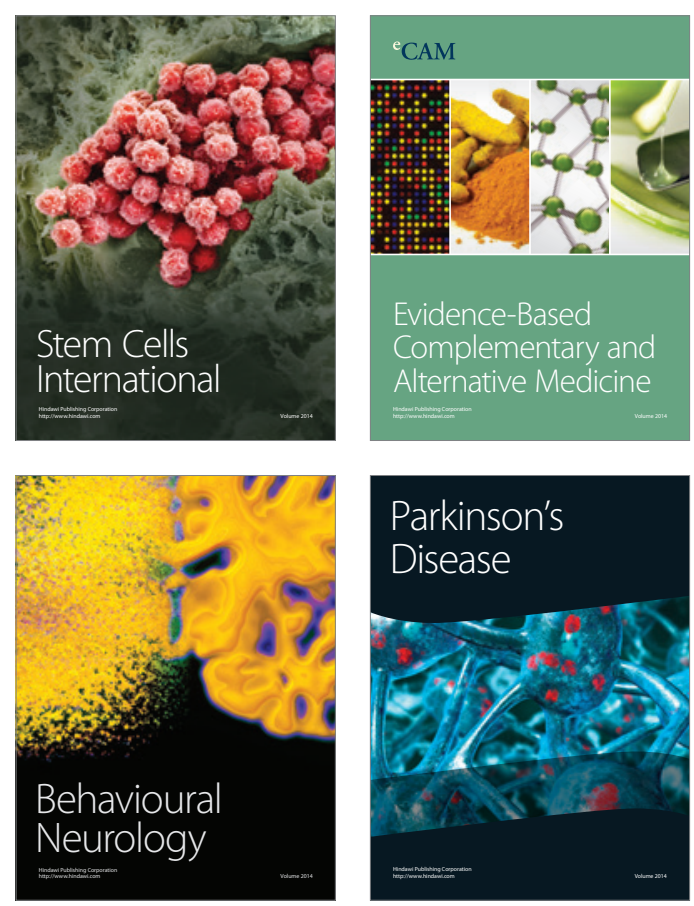

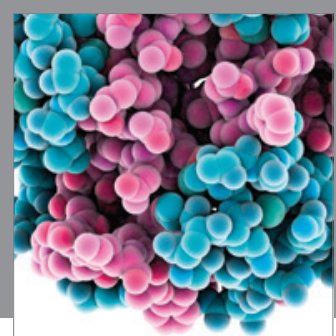

Journal of
Diabetes Research

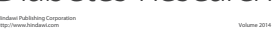

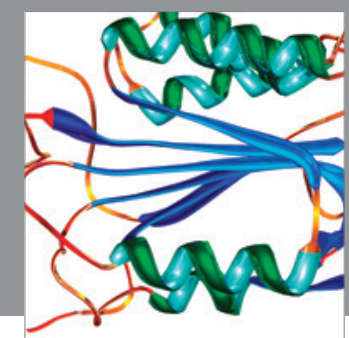

Disease Markers
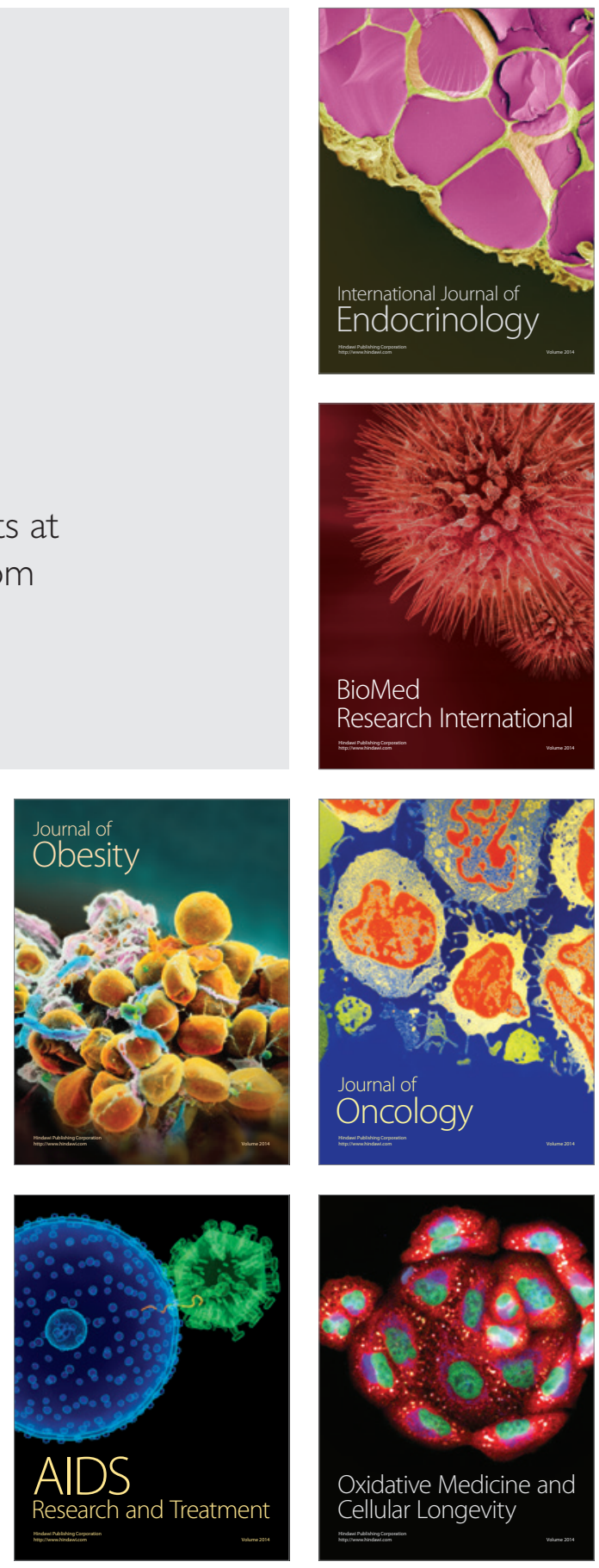